\title{
INDICADORES DE QUALIDADE DE SOLOS DE ÁREA DE MINERAÇÃO E METALURGIA DE CHUMBO. II - MESOFAUNA E PLANTAS ${ }^{(1)}$
}

\author{
Yara Jurema Barros ${ }^{(2)}$, Vander de Freitas Melo ${ }^{(3)}$, Klaus Dieter \\ Sautter ${ }^{(4)}$, Brenda Buschle ${ }^{(5)}$, Edilson Batista de Oliveira ${ }^{(6)}$, Júlio \\ César Rodrigues de Azevedo( ${ }^{(5)}$, Luiz Cláudio de Paula Souza ${ }^{(3)} \&$ \\ Larissa Kummer ${ }^{(7)}$
}

\begin{abstract}
RESUMO
A influência do manejo ou a adição de contaminante ao solo, normalmente, induz uma resposta mais rápida sobre a mesofauna do solo do que em outros atributos pedológicos, o que torna esses organismos bons indicadores de qualidade ambiental. Os objetivos deste trabalho foram identificar e quantificar os grupos de organismos da mesofauna dos solos e determinar os teores de $\mathrm{Pb}$ e $\mathrm{Zn}$ de plantas da área de mineração e metalurgia de $\mathrm{Pb}$, no município de Adrianópolis (PR), de modo que fossem gerados indicadores biológicos da qualidade desses solos. Os solos selecionados apresentaram as seguintes características em relação às formas de contaminação: solo 1 - referência (mata nativa); solo 2 - resíduos incorporados ao perfil; solos 3 e 6 - próximos às chaminés da fábrica, com potencial de aporte de material particulado; e solo 5 - grande volume de rejeitos sobre o solo. Foram utilizados funis de Berlese, coletando-se amostras na profundidade de 0 a $5 \mathrm{~cm}$ (20 funis $\times 5$ solos $\times 1$ profundidade $\times 4$ épocas $=400$ amostras). Após separação da mesofauna, procedeu-se à triagem e identificação dos organismos com o auxílio de lupa. Amostras de formiga foram digeridas com $\mathrm{HNO}_{3}$ concentrado em sistema fechado de micro-ondas, e os teores de $\mathrm{Pb}$ e $\mathrm{Zn}$ foram determinados por espectroscopia de emissão atômica com plasma indutivamente acoplado (ICPAES). Plantas da família Poaceae foram coletadas em todos os solos e, após digestão das amostras da parte aérea e da raiz pelo método nítrico-perclórico,
\end{abstract}

(1) Parte do trabalho de mestrado do primeiro autor apresentado ao Programa de Pós-Graduação em Ciência do Solo, Universidade Federal do Paraná - UFPR. Recebido para publicação em julho de 2009 e aprovado em maio de 2010.

(2) Mestre em Ciência do Solo, Universidade Federal do Paraná - UFPR. Rua dos Funcionários 1540, Juvevê, CEP 80035-050 Curitiba (PR). E-mail: yarajuba@gmail.com

(3) Departamento de Solos e Engenharia Agrícola, UFPR. Bolsista CNPq. E-mail: vanderfm@ufpr.br; lcsouza@ufpr.br

(4) Universitário Positivo, Mestrado em Gestão Ambiental, Rua Prof. Pedro Viriato Parigot de Souza 5300, Campo Comprido, CEP 81280-330 Curitiba (PR). E-mail: ksautter@up.edu.br

(5) Departamento de Química e Biologia, Universidade Tecnológica Federal do Paraná - UTFPR. Av. Sete de Setembro 3165 , CEP 80203-901 Curitiba (PR). E-mail: b.buschle@gmail.com; jcrazevedo@utfpr.edu.br

(6) Embrapa Florestas, Estrada da Ribeira, km 111, Caixa Postal 319, CEP 83411-000 Colombo (PR). E-mail: edilson@cnpf.embrapa.br

(7) Departamento de Engenharia Ambiental, UTFPR. E-mail: lkummer@utfpr.edu.br 
determinaram-se os teores de $\mathrm{Pb}$ e $\mathrm{Zn}$ por ICP-AES. O número total de organismos dos 21 grupos identificados e o Índice de Qualidade Ambiental da Mesofauna não foram bons indicadores do nível de contaminação dos solos por metais pesados. A ocorrência e distribuição de espécies isoladas mostraram-se mais eficientes nesse propósito. A melhor qualidade ambiental do solo 1 (teores naturais de $\mathbf{P b}$ - solo de referência) foi atestada pela maior riqueza de grupos de organismos e ocorrência de representantes dos grupos Pseudoscorpiones, Mollusca e Isopoda apenas nesse solo. Os grupos Aracnídeos e Psocoptera também foram considerados bons indicadores ambientais, com incremento de suas populações nos solos com maiores teores de metais pesados (solos $2,3 \mathrm{e} 5)$, possivelmente devido à menor ocorrência de organismos competidores/predadores desses grupos. Os teores de metais pesados nos indivíduos do grupo Formicidae tiveram relação direta com os teores de $\mathrm{Pb}$ extraídos com $\mathrm{HNO}_{3}$ 0,5 $\mathrm{mol} \mathrm{L}^{-1}$ no solo. Quanto ao acúmulo de metais pesados nas plantas coletadas na área, com exceção do solo 1, todas as espécies encontravamse sob efeito fitotóxico para $\mathrm{Pb}$ e $\mathrm{Zn}$, o que sugere a proibição de pastejo na área.

Termos de indexação: bioindicadores, contaminação ambiental, metais pesados, fitotoxidez por metais pesados.

\section{SUMMARY: SOIL QUALITY INDICATORS IN LEAD MINING AND METALURGY AREA. II - MESOFAUNA AND PLANTS}

The influence of soil management or the contaminant application to the soil, usually induce to a quicker response in the soil mesofauna than in other pedogenic properties; these organisms are therefore good environmental quality indicators. The aim of this study was to identify and quantify the organisms groups of the soil mesofauna and determine $\mathrm{Pb}$ and $\mathrm{Zn}$ contents in plants in the mining and metallurgy plant in Adrianópolis (PR), to originate biological indicators of the quality of these solis. At the selected locations the following contamination forms were analized: site 1 -reference (native wood); site 2 -residue incorporated in the profile; sites 3 and 6 -close to the chimneys of the plant, with potential import of particulate matter; site 5 -great waste volume covering the soil. Berlese funnels were utilized to collect samples from the 0 to $5 \mathrm{~cm}$ layer (20 funnels $x 5$ sites $x 1$ layer $x 4$ times $=400$ samples). After the separation of the mesofauna, the organisms were selected and identified. Ants samples were microwave digested with concentrated $\mathrm{HNO}_{3}$ and the $\mathrm{Pb}, \mathrm{Cu}, \mathrm{Ni}$ and $\mathrm{Zn}$ contents were determined by inductively coupled plasma - atomic emission Spectrometry (ICP-AES). Plants from Poaceae family were collected in all sites and the $\mathrm{Pb}, \mathrm{Cu}, \mathrm{Ni}$ and $\mathrm{Zn}$ contents determined after nitric-perchloric digestion, using ICP-AES. The total organism number from the 21 identified groups and the Mesofauna Environmental Quality Index were not good indicators of the heavy metal contamination level of the soil. The quantity and distribution of isolated species proved more efficient for this purpose. The best environmental quality at site 1(natural Pb levels - control soil) was evidenced by the highest diversity of organism groups and occurrence of the representative groups Pseudoscorpiones, Mollusca and Isopoda in this soil. The groups Arachinida and Psocoptera were also considered good environmental indicators, with population increases at sites with higher heavy metals content (sites 2, 3 and 5), possibly because of the reduced occurrence of competitor/predator organisms. The heavy metal content in the individuals of the group of Formicidae was directly related to the soil Pb content extracted with $0.5 \mathrm{~mol} \mathrm{~L}^{-1} \mathrm{HNO}_{3}$. In terms of heavy metal accumulation in native species, with exception of site 1, the soil had a phytotoxic effect of $\mathrm{Pb}$ and $\mathrm{Zn}$ on all species, suggesting that grazing should be banned.

\section{Index terms: biological indicators, environmental contamination, heavy metals, heavy metal} fitotoxicity.

\section{INTRODUÇÃO}

Não é fácil prever o número, o tipo e a atividade dos organismos que podem ser encontrados no solo, pois eles dependem, além do clima e da vegetação, de fatores do próprio solo, como umidade, temperatura, aeração, acidez, suprimento de nutrientes e de energia e grau de perturbação (Curry \& Good, 1992; Fisher \& Binkley, 2000).

O interesse pela avaliação da qualidade do solo vem aumentando, com a consciência de que se trata de um componente extremamente importante da 
biosfera, não só para a produção de alimentos, mas também na manutenção da qualidade ambiental. Alguns autores têm usado a mesofauna como indicador de poluição e degradação do solo (Christiansen, 1964; Kaiser et al., 1991; Stork \& Eggleton, 1992; Yamamoto et al., 1994; Sautter, 2001). A mesofauna edáfica é composta basicamente por ácaros (Acari) e colêmbolos (Collembola), além de coleópteros, alguns grupos de miriápodes, aracnídeos, diversas outras ordens de insetos e alguns oligoquetos e crustáceos. Os mais numerosos são os Oribatei (Acari: Cryptostigmata) e os Collembola (Hexapoda); juntos, eles constituem de 72 a $97 \%$, em proporção de indivíduos, da fauna total de artrópodes do solo (Singh \& Pillai, 1975).

As atividades tróficas desses animais incluem tanto o consumo de microrganismos e da microfauna como a fragmentação de material vegetal em decomposição. Como resultado de suas atividades no solo, a mesofauna pode aumentar em até seis vezes a velocidade de decomposição dos resíduos vegetais (Behan et al., 1978) e, assim, acelerar a mineralização dos nutrientes (Seasted, 1984). Além disso, a fauna do solo tem papel determinante em processos de melhoria de atributos físicos, como agregação, porosidade e infiltração de água, e no funcionamento biológico do solo (Sanginga et al., 1992). Nesse sentido, observa-se que a influência do manejo do solo sobre esse componente biológico apresenta, normalmente, resposta mais rápida do que em outros atributos pedológicos, servindo como indicador da qualidade dos solos e das alterações nos agroecossistemas (Paoletti \& Bressan, 1996).

Os organismos que habitam o solo são expostos aos metais pesados por contato dermal direto com a solução do solo ou por ingestão de partículas coloidais de solo contaminado (Lanno et al., 2004). Algumas espécies podem limitar a bioacumulação de alguns metais por excreção ativa e, ou, redução de absorção, mantendo assim baixa sobrecarga corporal, mesmo quando o ambiente possui alta concentração desses elementos (Rainbow, 2002). Após a absorção, os organismos podem ainda armazenar os metais pesados sob formas não tóxicas, como grânulos envoltos por proteína (Vijveret al., 2004). Entretanto, algumas espécies não conseguem regular a bioacumulação de metais não essenciais e, com isso, podem vir a sofrer efeitos tóxicos com as constantes exposições a altas contrações (Rainbow, 2002).

Muitas espécies de Collembola, por exemplo, têm sido consideradas suscetíveis aos metais pesados, resultando em decréscimo de sua abundância com o aumento dos teores desses elementos. Com isso, outras espécies aumentam sua abundância relativa nessas condições (Bengtsson \& Rundgren, 1988; Tranvik et al., 1993; Filser et al., 1995).

Nas plantas, os metais pesados podem, frequentemente, acumular-se em quantidades consideráveis nos tecidos e, inclusive, exceder os níveis de tolerância do organismo humano e animal, antes de prejudicarem a produção ou causarem efeitos fitotóxicos visíveis (Haan, 1981). Com exceção das espécies excludentes, a maioria das espécies vegetais que crescem em solos contaminados por metais pesados não consegue evitar a absorção desses elementos, mas somente limitar sua translocação (Baker, 1981). Existe grande variabilidade entre espécies de planta quanto à absorção de metais pesados (Xue \& Harrison, 1991). Contudo, mais importante que o total absorvido é o acúmulo de metais pesados em partes da planta que serão consumidas diretamente por animais e pelo homem. Como regra geral, o conteúdo de metais pesados decresce na ordem: folhas > raízes de reserva > tubérculos $>$ sementes e frutos (Xue \& Harrison, 1991).

Os objetivos deste trabalho foram determinar os teores de metais pesados em plantas e identificar e quantificar os grupos de organismos da mesofauna de solos da área de mineração e metalurgia de $\mathrm{Pb}$, no município de Adrianópolis (PR), de modo que fossem gerados indicadores biológicos da qualidade desses solos.

\section{MATERIAL E MÉTODOS}

\section{Área de estudo, amostragem de solos, plantas e mesofauna}

A área de mineração e metalurgia de $\mathrm{Pb}$ situa-se no município de Adrianópolis (PR), na localidade de Panelas de Brejaúvas, distante $12 \mathrm{~km}$ da sede do município e próxima às margens do rio Ribeira, na divisa com o Estado de São Paulo. Em 1995, após 50 anos de atividade, uma empresa mineradora encerrou suas atividades, deixando a céu aberto, sem nenhuma proteção, aproximadamente $177 \mathrm{Gg}$ de resíduos de beneficiamento de $\mathrm{Pb}$ (Eysink, 1988).

A compartimentalização da paisagem em unidades mais homogêneas, com menor variabilidade das classes de solos, usando o geoprocessamento, e a identificação de diferentes ambientes em função da forma de contaminação possibilitaram uma amostragem mais representativa da área sob influência direta das atividades de mineração e metalurgia de $\mathrm{Pb}$ (linha mais espessa na Figura 1). Os critérios para seleção dos locais de amostragem dos solos foram apresentados por Andrade et al. (2009a) e suas características encontram-se no quadro 1.

Foram realizadas quatro coletas (22 de maio, 3 de setembro e 26 de novembro de 2007 e 28 de janeiro de 2008) em quadrantes no entorno dos pontos selecionados (Figura 1 e Quadro 1). A área estabelecida para retirada da amostra composta de solo em cada época foi de 1,5 x 1,5 m. O objetivo das quatro coletas ao longo do tempo foi avaliar a flutuação biológica dos solos devido, principalmente, às alterações nas condições climáticas. Os dados de temperatura média e precipitação pluvial, provenientes de médias diárias 


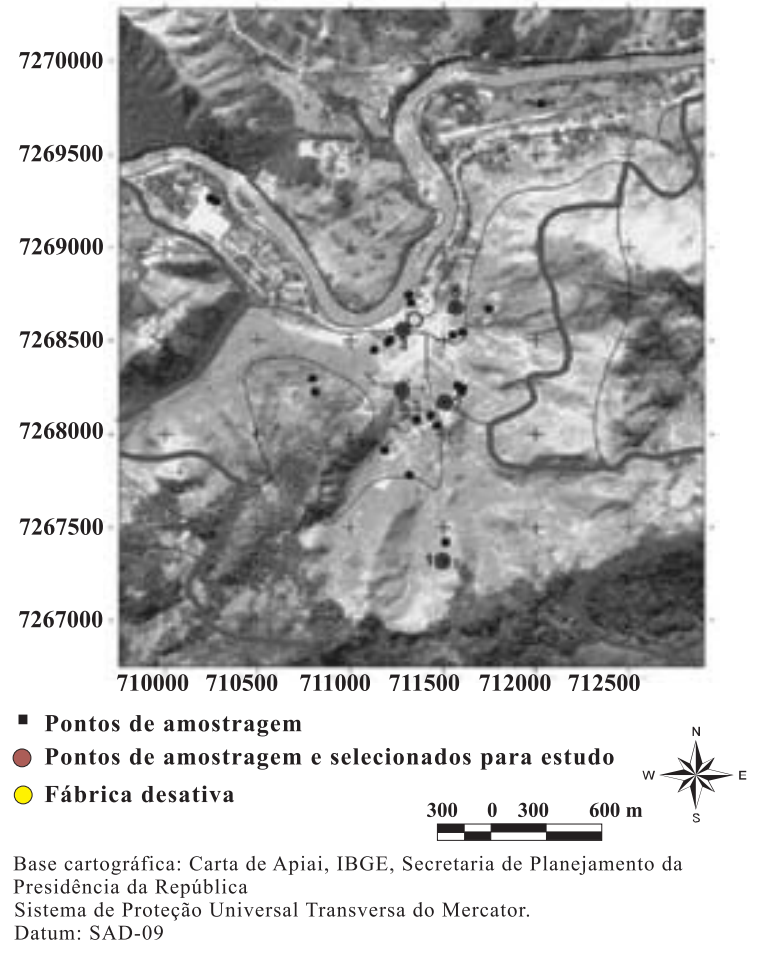

Figura 1. Foto aérea georreferenciada com os compartimentos geomorfológicos (linhas mais finas), localização da fábrica abandonada e locais de coleta $(1,2,3,5$ e 6) dentro da área selecionada para o estudo (linha mais espessa). Os pontos menores representam a coleta prévia de solos para reconhecimento da área e definição dos ambientes em função das diferentes formas de contaminação, conforme detalhes apresentados por Andrade et al. (2009a).

da região, podem ser visualizados na figura 2. Para obtenção da amostra composta, ainda no campo, foram homogeneizadas cerca de 10 amostras simples, retiradas de 0 a $5 \mathrm{~cm}$ no interior do quadrante previamente estabelecido. Com esses procedimentos, coletaram-se 20 amostras compostas: 5 solos $\mathrm{x} 1$ profundidade x 4 épocas de coleta.

No laboratório, a amostra de solo foi seca ao ar, moída e passada em peneira de plástico de malha de $2 \mathrm{~mm}$ (TFSA), para as seguintes determinações: umidade de campo (método gravimétrico); análise textural (método da pipeta); capacidade de campo (mesa de tensão); $\mathrm{pH}$ em água; $\mathrm{Al}^{3+}, \mathrm{Ca}^{2+}, \mathrm{Mg}^{2+}, \mathrm{K}^{+}$e $\mathrm{Na}^{+}$ trocáveis e acidez potencial não trocável $(\mathrm{H})$ (Embrapa, 1999); P disponível (Olsen \& Sommers, 1982); C orgânico (UFPR, 2003); e N total (Jackson, 1970). Após extração com solução de $\mathrm{HNO}_{3}$ 0,5 mol L-1 fervente (Knudsen et al., 1986; Martins et al., 2004) e com $\mathrm{HF}$ e $\mathrm{HNO}_{3}$ concentrados e $\mathrm{H}_{2} \mathrm{O}_{2} 30 \%$ (vol/vol) (teores totais) (Lim \& Jackson, 1986; Melo et al., 2002), os teores de $\mathrm{Pb}$ e $\mathrm{Zn}$ foram determinados por espectroscopia de emissão atômica com plasma acoplado indutivamente (ICP-AES). Os resultados das análises físicas e químicas e os teores de $\mathrm{Pb}$ e $\mathrm{Zn}$ são apresentados nos quadros 2,3 e 4, respectivamente.

Andrade et al. (2009b) avaliaram a disponibilidade de metais pesados para girassol, aveia-preta e gramabatatais, em amostras de solos retiradas dos mesmos locais do presente estudo, com diferentes métodos de extração (DTPA-TEA pH 7,3; $\mathrm{Ca}\left(\mathrm{NO}_{3}\right)_{2} 0,5 \mathrm{~mol} \mathrm{~L}^{-1}$; $\mathrm{HNO}_{3} 1,0$ e $4 \mathrm{~mol} \mathrm{~L}^{-1}$; e água-régia $\left(\mathrm{HNO}_{3} / \mathrm{HCl}\right.$ concentrados - 3:1), e concluíram que o $\mathrm{HNO}_{3}$ $0,5 \mathrm{~mol} \mathrm{~L}^{-1}$ fervente foi o método que melhor se correlacionou com a absorção desses metais pelas plantas.

A mesofauna edáfica foi coletada com 20 repetições no interior dos mesmos quadrantes (quatro coletas de maio a janeiro) e profundidade (0 a $5 \mathrm{~cm})$, com o auxílio de funis de Berleze: 5 solos x 1 profundidade $\mathrm{x}$ 4 coletas $\times 20$ repetições $=400$ amostras. Após a coleta das amostras indeformadas, os funis foram devidamente ensacados, para evitar a perda de umidade, e transportados até o laboratório.

Plantas da família Poaceae (gramíneas) (solos 1 e 3: capim-colonião - Panicum maximum; solos 3 e 5: grama-batatais - Paspalum notatum; solo 6: capimelefante - Pennisetum purpureum) foram coletadas, separando-se parte aérea e raiz. A escolha da espécie de Poaceae foi em função da cobertura vegetal de cada local (Quadro 1). A coleta também foi realizada em quatro épocas do ano, nas mesmas datas de amostragens dos solos (20 amostras). No laboratório, as amostras de plantas foram lavadas (água corrente, solução de detergente a 0,1 \% e água deionizada - Jones Jr. et al., 1990), secas a $60^{\circ} \mathrm{C}$, até peso constante, e submetidas a moagem (Embrapa, 1999).

\section{Análises na mesofauna}

\section{Composição da mesofauna}

Em laboratório, a mesofauna edáfica foi extraída pelo método do funil de Berleze modificado (Sautter et al., 1999), em mesas expositoras, durante sete dias, por meio de aquecimento produzido por lâmpadas incandescentes colocadas sobre as amostras de solo (Mussury et al., 2002).

Os conteúdos dos frascos foram transferidos para placas de Petri, nas quais se procedeu à triagem, identificação e separação dos organismos com o auxílio de lupa. Esse procedimento foi realizado individualmente nas amostras de solo coletadas em cada local (400 amostras). Com base no volume dos funis, o número de organismos encontrados de cada grupo de mesofauna foi expresso por volume de solo $\left(\mathrm{dm}^{3}\right)$.

\section{Teores de $\mathrm{Pb}$ e $\mathrm{Zn}$ em formigas}

Devido à pequena quantidade de massa das formigas para a digestão, preparou-se apenas uma amostra desses organismos por solo, por meio da 
Quadro 1. Localização, classificação dos solos e características dos locais de amostragem identificadas em campo

\begin{tabular}{|c|c|c|c|c|c|}
\hline \multirow[b]{2}{*}{ Solo } & \multicolumn{2}{|c|}{ UTM (22J) } & \multirow[b]{2}{*}{ Altitude } & \multirow[b]{2}{*}{ Classe de solo } & \multirow[b]{2}{*}{ Observações } \\
\hline & $\begin{array}{l}\text { N-S (m) } \\
\text { Latitude }\end{array}$ & $\begin{array}{c}\text { E-W (m) } \\
\text { Longitude }\end{array}$ & & & \\
\hline 1 & $7267313 \mathrm{~S}$ & $711502 \mathrm{~W}$ & $546 \mathrm{~m}$ & $\begin{array}{l}\text { Neossolo } \\
\text { Litólico }\end{array}$ & $\begin{array}{l}\text { Solo de referência sob mata nativa e capim-colonião (Panicum } \\
\text { maximum) no sub-bosque. Graças à grande altitude do local em } \\
\text { relação à fábrica (diferença de cota de } 380 \mathrm{~m} \text { ), não havia evi- } \\
\text { dências da influência direta das atividades de mineração no solo. }\end{array}$ \\
\hline 2 & 7268164 & 711513 & $326 \mathrm{~m}$ & $\begin{array}{l}\text { Cambissolo } \\
\text { Háplico }\end{array}$ & $\begin{array}{l}\text { Localizado em posição intermediária da encosta, representando } \\
\text { condição onde ocorreu incorporação de rejeito grosseiro e de } \\
\text { coloração escura no perfil de solo, devido à deposição de colúvio } \\
\text { das áreas mais altas. Cobertura vegetal composta por grama- } \\
\text { batatais (Paspalum notatum) na maior parte de sua extensão. }\end{array}$ \\
\hline 3 & 7268555 & 711287 & $165 \mathrm{~m}$ & $\begin{array}{l}\text { Neossolo } \\
\text { Litólico }\end{array}$ & $\begin{array}{l}\text { Localizado próximo à fábrica, com grande volume de serapilheira, } \\
\text { com os horizontes do solo preservados e sem incorporação de } \\
\text { rejeitos sólidos. Esse local representou os solos que potencialmente } \\
\text { receberam deposição de material particulado oriundo do processo } \\
\text { de fusão do } \mathrm{Pb} \text {, por meio da emissão de fumaça pelas chaminés. } \\
\text { Cobertura vegetal composta por árvores da família das } \\
\text { leguminosas (Leucaena sp.) e capim-colonião (Panicum maximum) } \\
\text { no sub-bosque. }\end{array}$ \\
\hline 5 & 7268070 & 711360 & $316 \mathrm{~m}$ & $\begin{array}{l}\text { Mistura de solo } \\
\text { mais rejeito } \\
\text { grosseiro }\end{array}$ & $\begin{array}{l}\text { Pilhas de rejeitos na superfície do solo e resíduos ainda frescos } \\
\text { visivelmente incorporados ao perfil. A cobertura vegetal, assim } \\
\text { como do local 2, era constituída de grama-batatais (Paspalum } \\
\text { notatum), em sua maior parte, porém menos viçosa que no local } 2 .\end{array}$ \\
\hline 6 & 7268671 & 711572 & $202 \mathrm{~m}$ & $\begin{array}{l}\text { Neossolo } \\
\text { Quartzarênico }\end{array}$ & $\begin{array}{l}\text { Encontrava-se sob condições similares às do local } 3 \text {, próximo à } \\
\text { fábrica e sujeito à contaminação com } \mathrm{Pb} \text { particulado pela } \\
\text { deposição atmosférica. A cobertura vegetal do local } 6 \text { é de mata } \\
\text { secundária, e as espécies preponderantes são diferentes do local } 1 \text {, } \\
\text { destacando-se samambaias (Pteridium aquilinum) e capim- } \\
\text { elefante (Pennisetum purpureum) no sub-bosque. }\end{array}$ \\
\hline
\end{tabular}

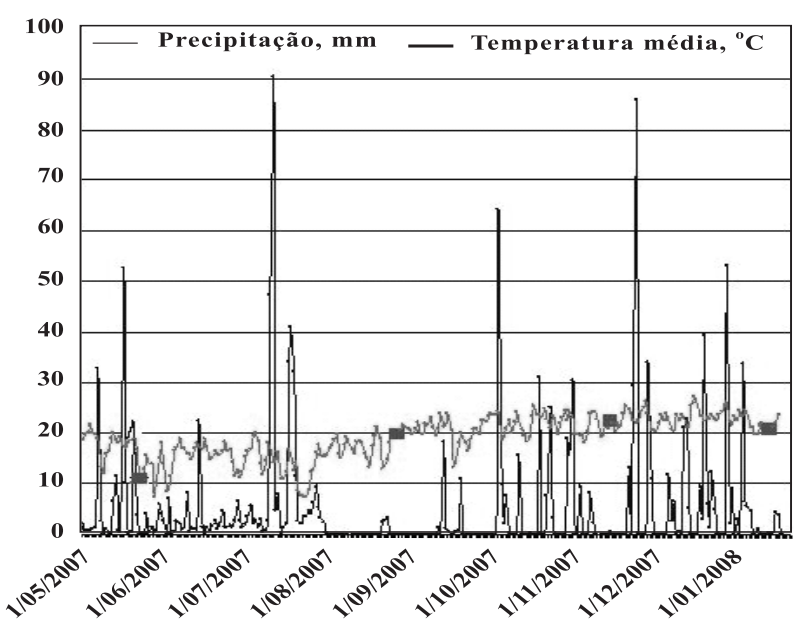

Figura 2. Precipitação pluvial e temperatura média na região de Adrianópolis durante a época de amostragem dos solos. Os pontos no gráfico de temperatura representam os dias de coleta, o que evidencia a condição de menor temperatura da região na coleta de maio. Fonte: Dados da Estação Experimental de Cerro Azul (distante, aproximadamente, $35 \mathrm{~km}$ da área de estudo), fornecidos pelo SIMEPAR (PR). mistura e homogeneização de 80 amostras simples (formigas extraídas do solo de 20 funis x 4 coletas).

Para garantir a remoção das partículas de solo aderidas às formigas, as amostras foram lavadas em água destilada por 10 vezes. Após secagem em estufa a $50{ }^{\circ} \mathrm{C}$, até peso constante, as amostras foram digeridas com $\mathrm{HNO}_{3}$ concentrado em sistema fechado de micro-ondas (Eeva et al., 2005). Os teores de $\mathrm{Pb}$ e Zn foram determinados por espectroscopia de emissão atômica com plasma acoplado indutivamente (ICPAES).

\section{Teores totais de metais pesados em plantas}

As amostras da parte aérea e raiz foram digeridas pelo método nítrico-perclórico (Embrapa, 1999). Os teores de $\mathrm{Pb}$ e $\mathrm{Zn}$ foram determinados por ICP-AES.

\section{Análise estatística}

O tratamento estatístico dos dados foi realizado por três métodos: diferenciação dos solos por meio da análise de componentes principais (ACP); obtenção de índice de qualidade ambiental relativo à densidade populacional dos grupos da mesofauna no solo (IQAMe); e análise de correlação simples (Pearson) entre a densidade populacional dos grupos da mesofauna e as 
Quadro 2. Propriedades físicas da camada de 0 a 5 cm dos solos

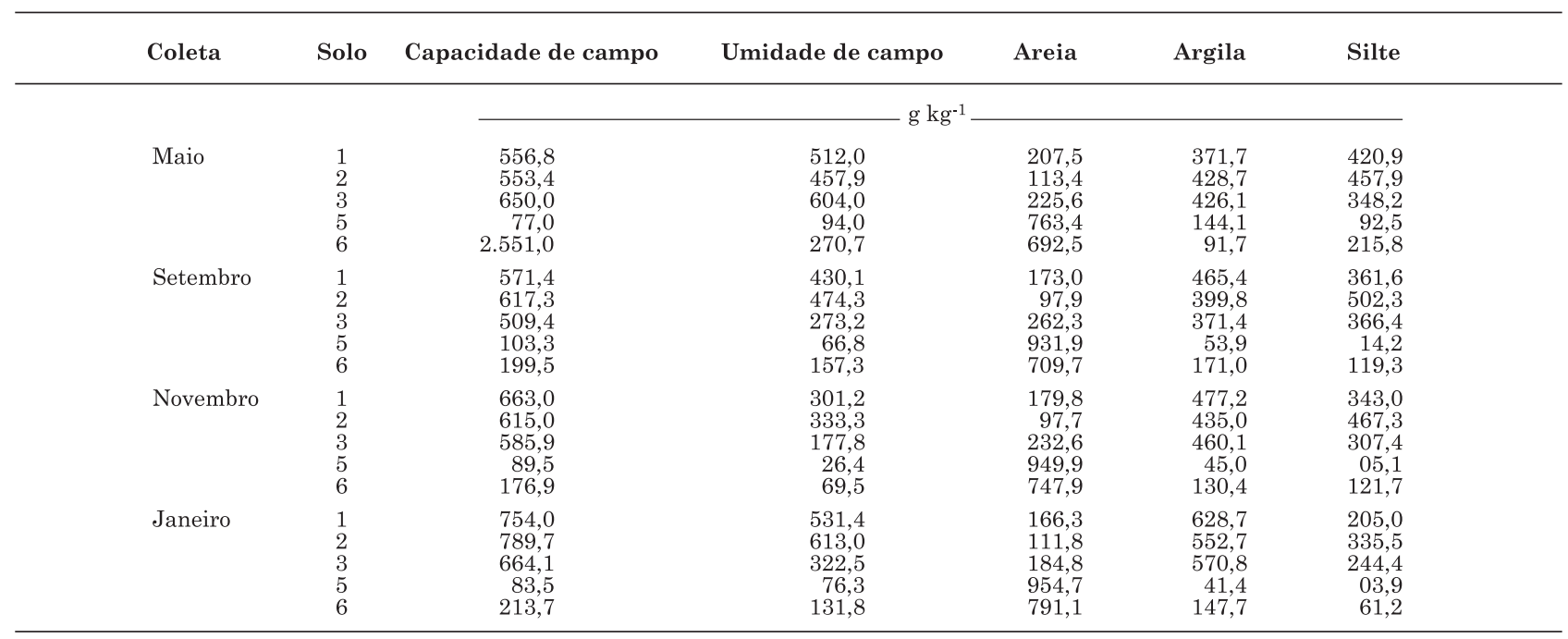

Quadro 3. Propriedades químicas da camada de 0 a 5 cm dos solos

\begin{tabular}{|c|c|c|c|c|c|c|c|c|c|c|c|c|c|c|c|}
\hline Coleta & Solo & $\mathbf{p H}$ & $\mathbf{H}$ & $\mathrm{Al}^{3+}$ & $\mathrm{Na}^{+}$ & $\mathbf{K}^{+}$ & $\mathrm{Ca}^{2+}$ & $\mathrm{Mg}^{2+}$ & $\mathbf{S}$ & $\begin{array}{c}\text { CTC } \\
\text { total }\end{array}$ & V & $\mathrm{CO}$ & $\mathbf{N}$ & $\begin{array}{c}\text { Relação } \\
\text { C/N }\end{array}$ & $\mathbf{P}$ \\
\hline & & & & & & $-\mathrm{cm}$ & $\mathrm{l}_{\mathrm{c}} \mathrm{kg}^{-1}$ & & & & $\%$ & $-\mathrm{g} \mathrm{l}$ & ${ }^{-1}$ & & $\mathrm{mg} \mathrm{kg}^{-1}$ \\
\hline \multirow[t]{5}{*}{ Maio } & 1 & 6,5 & 4,0 & 0,0 & 0,08 & 0,34 & 17,4 & 6,3 & 24,1 & 28,1 & 85,8 & 50,3 & 6,9 & 7,2 & 5,6 \\
\hline & 2 & 6,3 & 5,2 & 0,0 & 0,07 & 0,33 & 20,3 & 4,2 & 24,9 & 30,1 & 82,7 & 41,7 & 5,1 & 8,1 & 3,9 \\
\hline & 3 & 6,9 & 2,4 & 0,0 & 0,13 & 1,68 & 23,7 & 4,2 & 29,7 & 32,1 & 92,5 & 74,7 & 8,7 & 8,6 & 13,7 \\
\hline & 5 & 7,7 & 0,0 & 0,0 & 0,40 & 0,83 & 1,8 & 0,3 & 3,3 & 3,3 & 100,0 & 11,5 & 0,1 & 104,6 & 5,9 \\
\hline & 6 & 5,3 & 5,2 & 0,0 & 0,06 & 0,32 & 3,6 & 1,2 & 5,2 & 10,4 & 49,8 & 30,8 & 2,0 & 15,8 & 4,3 \\
\hline \multirow[t]{5}{*}{ Setembro } & 1 & 6,3 & 5,2 & 0,0 & 0,05 & 0,48 & 13,9 & 5,0 & 19,4 & 24,6 & 78,9 & 58,2 & 7,0 & 8,4 & 4,4 \\
\hline & 2 & 7,0 & 0,8 & 0,0 & 0,07 & 0,28 & 23,7 & 2,5 & 26,6 & 27,4 & 97,1 & 51,7 & 5,3 & 9,8 & 3,3 \\
\hline & 3 & 7,0 & 2,0 & 0,0 & 0,07 & 0,73 & 19,3 & 2,0 & 22,1 & 24,1 & 91,7 & 50,0 & 5,9 & 8,5 & 20,6 \\
\hline & 5 & 7,8 & 0,0 & 0,0 & 0,23 & 0,45 & 3,3 & 0,4 & 4,4 & 4,4 & 100,0 & 26,6 & 0,9 & 29,0 & 6,5 \\
\hline & 6 & 4,8 & 3,3 & 0,3 & 0,02 & 0,26 & 1,3 & 0,1 & 1,7 & 5,3 & 32,2 & 19,6 & 1,7 & 11,4 & 4,8 \\
\hline \multirow[t]{5}{*}{ Novembro } & 1 & 5,7 & 10,0 & 0,0 & 0,07 & 0,45 & 17,2 & 5,4 & 23,1 & 33,1 & 69,8 & 53,5 & 7,2 & 7,4 & 4,6 \\
\hline & 2 & 6,9 & 2,0 & 0,0 & 0,07 & 0,18 & 24,4 & 6,1 & 30,7 & 32,7 & 93,9 & 50,3 & 6,7 & 7,6 & 5,7 \\
\hline & 3 & 6,8 & 2,4 & 0,0 & 0,06 & 1,08 & 20,5 & 2,2 & 23,8 & 26,2 & 90,9 & 49,5 & 6,2 & 8,0 & 17,1 \\
\hline & 5 & 7,8 & 0,0 & 0,0 & 0,27 & 0,51 & 3,6 & 0,4 & 4,7 & 4,7 & 100,0 & 13,8 & 0,3 & 40,2 & 7,7 \\
\hline & 6 & 5,1 & 2,2 & 0,2 & 0,02 & 0,27 & 0,7 & 0,7 & 1,7 & 4,1 & 40,9 & 16,1 & 1,2 & 14,0 & 3,8 \\
\hline \multirow[t]{5}{*}{ Janeiro } & 1 & 6,7 & 2,4 & 0,0 & 0,08 & 0,45 & 21,0 & 5,6 & 27,1 & 29,5 & 91,9 & 81,4 & 8,2 & 10,0 & 3,8 \\
\hline & 2 & 7,2 & 0,8 & 0,0 & 0,08 & 0,23 & 22,4 & 6,9 & 29,6 & 30,4 & 97,4 & 42,1 & 7,1 & 5,9 & 7,1 \\
\hline & 3 & 6,4 & 4,8 & 0,0 & 0,08 & 0,92 & 50,6 & 4,3 & 55,9 & 60,7 & 92,1 & 57,7 & 6,7 & 8,7 & 15,9 \\
\hline & 5 & 7,5 & 0,0 & 0,0 & 0,34 & 0,71 & 2,3 & 0,3 & 3,6 & 3,6 & 100,0 & 19,4 & 0,6 & 33,8 & 5,2 \\
\hline & 6 & 5,5 & 3,1 & 0,1 & 0,02 & 0,33 & 2,6 & 0,7 & 3,6 & 6,8 & 53,0 & 26,8 & 0,6 & 46,6 & 3,1 \\
\hline
\end{tabular}

propriedades físicas (Quadro 2) e químicas (Quadro 3) e os teores de $\mathrm{Pb}$ e $\mathrm{Zn}$ (Quadro 4) dos solos.

O primeiro método consistiu da análise por componentes principais (ACP), com o objetivo de verificar quais grupos da mesofauna poderiam ser utilizados para diferenciar ou indicar similaridades entre as amostras de diferentes solos e épocas de coletas. Realizou-se processo de seleção prévia de grupos da mesofauna: 12 grupos (Quadro 5), os quais representaram 99 \% da variância total dos grupos.

No segundo método (IQAMe), com base nos grupos da mesofauna selecionados na ACP (Quadro 5), fez-se a estandardização dos dados $(Z)$ :

$$
Z=\frac{X-\mu}{\sigma}
$$

em que $X$ é o valor do parâmetro; $\mu$, média geral dos dados; e $\sigma$, o desvio-padrão.

Posteriormente, realizou-se a multiplicação de cada dado estandardizado pelo peso que a variável de origem representava na primeira componente principal. $\mathrm{O}$ IQAMe foi obtido pela soma de todas as variáveis da mesofauna, o que gerou um único valor por solo e época de amostragem.

Para representação do nível de significância dos coeficientes de correlação $(r)$ nas correlações simples 
Quadro 4. Teores de $\mathrm{Pb}$ e $\mathrm{Zn}$ totais (HF) e extraídos com $\mathrm{HNO}_{3}$ na camada de 0 a 5 cm dos $\operatorname{solos}^{(1)}$

\begin{tabular}{|c|c|c|c|c|c|}
\hline \multirow{2}{*}{ Coleta } & \multirow{2}{*}{ Solo } & \multicolumn{2}{|c|}{$\mathrm{HF}$ e $\mathrm{HNO}_{3}$ concentrados $+\mathrm{H}_{2} \mathrm{O}_{2}$} & \multicolumn{2}{|c|}{$\mathrm{HNO}_{3} \quad 0,5 \mathrm{~mol} \mathrm{~L}^{-1}$} \\
\hline & & $\mathrm{Pb}$ & $\mathrm{Zn}$ & $\mathbf{P b}$ & $\mathrm{Zn}$ \\
\hline & & & & & \\
\hline \multirow[t]{5}{*}{ Maio } & 1 & 464,5 & 293,7 & 420,6 & 81,9 \\
\hline & 2 & 5761,1 & 317,2 & 4361,1 & 242,2 \\
\hline & 3 & 14179,7 & 1196,3 & 9467,2 & 985,2 \\
\hline & 5 & 17261,5 & 23434,6 & 2410,5 & 2573,7 \\
\hline & 6 & 734,6 & nd & 472,5 & nd \\
\hline \multirow[t]{5}{*}{ Setembro } & 1 & 577,9 & 394,1 & 520,9 & 93,2 \\
\hline & 2 & 5322,2 & 424,1 & 4779,3 & 282,3 \\
\hline & 3 & 15248,3 & 1160,8 & 14457,9 & 1071,4 \\
\hline & 5 & 19237,5 & 23337,3 & 2499,0 & 2528,5 \\
\hline & 6 & 1301,9 & nd & 859,1 & nd \\
\hline \multirow[t]{5}{*}{ Novembro } & 1 & 813,2 & 211,8 & 677,9 & 108,5 \\
\hline & 2 & 6269,7 & 388,9 & 4153,5 & 228,9 \\
\hline & 3 & 14863,0 & 1222,4 & 12796,1 & 962,5 \\
\hline & 5 & 22109,3 & 33371,9 & 2849,5 & 2535,9 \\
\hline & 6 & 788,3 & 40,5 & 698,7 & 18,8 \\
\hline \multirow{5}{*}{ Janeiro } & 1 & 764,6 & 105,2 & 362,7 & 70,2 \\
\hline & 2 & 10205,8 & 796,8 & 2714,6 & 263,9 \\
\hline & 3 & 17460,9 & 1668,2 & 12007,5 & 808,9 \\
\hline & 5 & 25190,8 & 54238,4 & 1910,9 & 2527,0 \\
\hline & 6 & 560,1 & nd & 493,6 & nd \\
\hline
\end{tabular}

(1) nd: teores abaixo do nível de detecção do método analítico empregado (ICP-AES).

Quadro 5. Grupos de organismos selecionados ${ }^{(*)}$ para a análise por componentes principais (ACP) e para o índice de qualidade ambiental da mesofauna (IQAMe)

\begin{tabular}{|c|c|}
\hline Grupo & $\begin{array}{c}\text { Símbolo adotado } \\
\text { na ACP }\end{array}$ \\
\hline Mollusca & a1 \\
\hline Isopoda $\left({ }^{*}\right)$ & $\mathrm{a} 2$ \\
\hline Chilopoda & a3 \\
\hline Diplopoda $(*)$ & a4 \\
\hline Pauropoda & a5 \\
\hline Symphyla $(*)$ & a6 \\
\hline Pseudoscorpiones $(*)$ & a7 \\
\hline Arachnida $(*)$ & a8 \\
\hline Opiliones & a9 \\
\hline Acari $(*)$ & a10 \\
\hline Protura $(*)$ & a11 \\
\hline Diplura & a12 \\
\hline Thysanura & a13 \\
\hline Collembola Arthropleona (*) & a14 \\
\hline Collembola Symphypleona ${ }^{*}$ ) & a15 \\
\hline Isoptera & a16 \\
\hline Coleoptera $\left({ }^{*}\right)$ & a17 \\
\hline Larvas de Coleoptera & a18 \\
\hline Diptera & a19 \\
\hline Larvas de Diptera $\left(^{*}\right)$ & $\mathrm{a} 20$ \\
\hline Hymenoptera & a21 \\
\hline Formiga & a22 \\
\hline Homoptera & a23 \\
\hline Dermaptera & $\mathrm{a} 24$ \\
\hline Psocoptera $\left({ }^{*}\right)$ & a25 \\
\hline Orthoptera & $\mathrm{a} 26$ \\
\hline Thysanoptera & a27 \\
\hline
\end{tabular}

(terceiro método), adotou-se a seguinte notação: ${ }^{* * *}-r$ significativo a $0,1 \%$; $\mathrm{e}^{* *} \mathrm{r}$ significativo a $1 \%$.

\section{RESULTADOS E DISCUSSÃO}

\section{Indicadores da mesofauna}

O solo 1 apresentou o maior número de grupos da mesofauna na camada de 0 a $5 \mathrm{~cm}$ de profundidade (Quadro 6), o que é um forte indicativo de melhor qualidade ambiental. Barros et al. (2010) observaram maior desenvolvimento de bactérias em amostras coletadas no mesmo solo e profundidade nos meses de maio e setembro.

Observou-se que o grupo com maior densidade populacional foi o Acari (classe Arachnida) (Quadro 6), com diferenças em suas proporções relativas ao total de organismos dependendo do solo e da época de coleta. Para o solo 1, a percentagem de ácaros manteve-se em torno de 49 a $69 \%$; solo 2, de 63 a $70 \%$; e para o solo 5, de 73 a $85 \%$ (Quadro 6). Nos solos 3 e 6 observou-se maior variação. A baixa densidade populacional total de organismos nos solos 2 e 5 foi responsável pelo aumento da percentagem de ácaros nesses sítios. Outros autores observaram o predomínio do grupo Acari na mesofauna do solo (Franklin et al., 2005), chegando a $78 \%$ em floresta e 94,7\% em pastagem (Teixeira \& Schubart, 1988). Segundo Tousignant \& Coderre (1992) e Sautter \& Santos (1994), os Acari são os primeiros colonizadores de áreas degradadas. 
A população de Collembola Arthropleona para o solo 1, que girava em torno de 2 a $7 \%$ nas coletas de maio e setembro, passou para 20 a $25 \%$ em novembro e janeiro. Já indivíduos de Collembola Symphypleona foram detectados somente na coleta de setembro, na qual representaram, praticamente, $10 \%$ do total de organismos. Somando-se os dois grupos de Collembola nas quatro coletas, verifica-se densidade populacional muito maior no solo 1 ( 1 : 133,$7 ; 3: 86,8 ; 6: 55,5 ; 5$ : 5,2; $2: 2,79$ indivíduos $\mathrm{dm}^{-3}$ de solo), o que pode ser devido ao efeito negativo da atividade mineradora nos solos 2 a 6 . Estudos realizados por Stork \& Eggleton (1992) apontaram que os Collembola foram bons indicadores biológicos da qualidade do solo e do ecossistema.
Além dos altos teores de $\mathrm{Pb}$ (Quadro 4), a inexpressiva densidade populacional de Collembola no solo 5 pode ser atribuída à reduzida cobertura vegetal e ao grande volume de rejeitos na superfície e incorporados ao perfil do solo (Quadro 1): os baixos teores de argila desse solo (Quadro 2) são atribuídos ao tamanho grosseiro dos rejeitos. De acordo com Christiansen (1964), Kaiser et al. (1991) e Sautter (2001), a mesofauna edáfica é altamente sensível à compactação do solo. Devido ao trânsito de máquinas na área do solo 5 durante as atividades da fábrica para o transporte e destinação dos rejeitos, na ocasião da amostragem observou-se extrema dureza e resistência do solo à penetração das ferramentas de coleta de amostra.

Quadro 6. Densidade populacional da mesofauna edáfica nos solos

\begin{tabular}{|c|c|c|c|c|c|}
\hline Grupo & Maio & Setembro & Novembro & Janeiro & Total \\
\hline & \multicolumn{5}{|c|}{ Indivíduos $\mathrm{dm}^{-3(1)}$} \\
\hline & & & Solo 1 & & \\
\hline Mollusca & 0,20 & 0,00 & 0,00 & 0,00 & 0,20 \\
\hline Isopoda & 3,38 & 1,39 & 0,40 & 1,00 & 6,17 \\
\hline Chilopoda & 0,00 & 0,60 & 0,20 & 0,00 & 0,80 \\
\hline Diplopoda & 1,59 & 0,00 & 0,00 & 0,80 & 2,39 \\
\hline Pauropoda & 0,00 & 0,20 & 5,57 & 3,78 & 9,55 \\
\hline Symphyla & 1,00 & 1,19 & 6,57 & 3,18 & 11,94 \\
\hline Pseudoscorpiones & 1,59 & 0,80 & 1,59 & 2,59 & 6,57 \\
\hline Arachnida & 1,99 & 1,19 & 1,19 & 1,39 & 5,76 \\
\hline Acari & 25,68 & 83,00 & 273,49 & 61,31 & 443,48 \\
\hline Protura & 0,00 & 1,00 & 6,97 & 2,79 & 10,76 \\
\hline Diplura & 2,79 & 2,19 & 1,59 & 1,99 & 8,56 \\
\hline Thysanura & 0,20 & 0,00 & 0,00 & 0,20 & 0,40 \\
\hline Collemb. Arthropleona & 1,19 & 8,76 & 79,02 & 31,65 & 120,62 \\
\hline Collemb. Symphypleona & 0,00 & 13,14 & 0,00 & 0,00 & 13,14 \\
\hline Coleoptera & 0,40 & 0,80 & 2,19 & 5,97 & 9,36 \\
\hline Larvas de Coleoptera & 0,00 & 0,40 & 0,00 & 0,60 & 1,00 \\
\hline Larvas de Diptera & 1,00 & 0,00 & 0,40 & 0,60 & 2,00 \\
\hline Formicidae & 5,37 & 13,93 & 5,37 & 4,18 & 28,85 \\
\hline Homoptera & 1,00 & 0,20 & 4,58 & 0,40 & 6,18 \\
\hline Psocoptera & 0,20 & 0,00 & 0,80 & 0,20 & 1,20 \\
\hline Outros & 1,39 & 3,98 & 3,58 & 1,39 & 10,34 \\
\hline \multirow[t]{2}{*}{ Total } & 48,96 & 132,76 & 394,11 & 124,00 & 699,83 \\
\hline & & & Solo 2 & & \\
\hline Mollusca & 0,00 & 0,00 & 0,00 & 0,00 & 0,00 \\
\hline Isopoda & 0,00 & 0,20 & 0,00 & 0,00 & 0,20 \\
\hline Chilopoda & 0,00 & 0,00 & 0,00 & 0,00 & 0,00 \\
\hline Diplopoda & 0,00 & 0,00 & 0,00 & 0,00 & 0,00 \\
\hline Pauropoda & 0,20 & 0,40 & 0,00 & 0,20 & 0,80 \\
\hline Symphyla & 0,00 & 0,20 & 0,00 & 0,20 & 0,40 \\
\hline Pseudoscorpiones & 0,00 & 0,00 & 0,00 & 0,00 & 0,00 \\
\hline Arachnida & 0,00 & 0,40 & 0,00 & 0,40 & 0,80 \\
\hline Acari & 19,11 & 20,30 & 11,74 & 34,63 & 85,78 \\
\hline Protura & 0,00 & 0,20 & 0,40 & 0,60 & 1,20 \\
\hline Diplura & 0,40 & 0,80 & 0,40 & 1,99 & 3,59 \\
\hline Thysanura & 0,00 & 0,00 & 0,00 & 0,00 & 0,00 \\
\hline Collemb. Arthropleona & 0,40 & 0,40 & 0,80 & 1,19 & 2,79 \\
\hline Collemb. Symphypleona & 0,00 & 0,00 & 0,00 & 0,00 & 0,00 \\
\hline Coleoptera & 0,20 & 0,00 & 0,00 & 0,80 & 1,00 \\
\hline Larvas de Coleoptera & 0,00 & 0,00 & 0,00 & 0,20 & 0,20 \\
\hline Larvas de Diptera & 0,00 & 0,00 & 0,00 & 0,00 & 0,0 \\
\hline Formicidae & 8,16 & 7,96 & 3,38 & 9,16 & 28,66 \\
\hline Homoptera & 0,20 & 0,20 & 0,00 & 0,00 & 0,40 \\
\hline Psocoptera & 0,00 & 0,20 & 0,00 & 0,00 & 0,20 \\
\hline Outros & 0,20 & 0,40 & 0,00 & 0,80 & 1,40 \\
\hline Total & 28,86 & 32,25 & 16,72 & 50,36 & 128,19 \\
\hline
\end{tabular}


Quadro 6. Continuação

\begin{tabular}{|c|c|c|c|c|c|}
\hline Grupo & Maio & Setembro & Novembro & Janeiro & Total \\
\hline & \multicolumn{5}{|c|}{ Indivíduos dm³ (1) } \\
\hline & \multicolumn{5}{|c|}{ Solo 3} \\
\hline Mollusca & 0,00 & 0,00 & 0,00 & 0,00 & 0,00 \\
\hline Isopoda & 0,00 & 0,00 & 0,20 & 0,00 & 0,20 \\
\hline Chilopoda & 0,00 & 0,00 & 0,20 & 0,00 & 0,20 \\
\hline Diplopoda & 0,60 & 0,00 & 0,00 & 0,00 & 0,60 \\
\hline Pauropoda & 0,20 & 2,79 & 2,19 & 2,99 & 8,17 \\
\hline Symphyla & 0,00 & 2,39 & 0,00 & 0,60 & 2,99 \\
\hline Pseudoscorpiones & 0,00 & 0,00 & 0,00 & 0,00 & 0,00 \\
\hline Arachnida & 0,00 & 31,45 & 8,36 & 4,58 & 44,39 \\
\hline Acari & 13,54 & 279,86 & 139,33 & 19,71 & 452,44 \\
\hline Protura & 0,00 & 0,20 & 0,60 & 0,60 & 1,40 \\
\hline Diplura & 0,40 & 2,39 & 0,40 & 1,39 & 4,58 \\
\hline Thysanura & 0,00 & 0,00 & 0,00 & 0,00 & 0,00 \\
\hline Collemb. Arthropleona & 3,38 & 29,46 & 26,67 & 3,78 & 63,29 \\
\hline Collemb. Symphypleona & 0,00 & 22,09 & 1,39 & 0,00 & 23,48 \\
\hline Coleoptera & 0,00 & 0,00 & 0,00 & 1,59 & 1,59 \\
\hline Larvas de Coleoptera & 0,00 & 0,00 & 24,88 & 0,20 & 25,08 \\
\hline Larvas de Diptera & 0,00 & 0,20 & 0,00 & 0,00 & 0,20 \\
\hline Formicidae & 5,57 & 5,57 & 3,58 & 11,15 & 25,87 \\
\hline Homoptera & 10,35 & 10,55 & 0,60 & 0,20 & 21,70 \\
\hline Psocoptera & 0,40 & 7,56 & 1,59 & 0,20 & 9,75 \\
\hline Outros & 2,99 & 8,56 & 12,14 & 2,59 & 26,28 \\
\hline \multirow[t]{2}{*}{ Total } & 37,42 & 403,26 & 222,53 & 49,56 & 712,77 \\
\hline & \multicolumn{5}{|c|}{ Solo 5} \\
\hline Mollusca & 0,00 & 0,00 & 0,00 & 0,00 & 0,00 \\
\hline Isopoda & 0,00 & 0,00 & 0,00 & 0,00 & 0,00 \\
\hline Chilopoda & 0,00 & 0,00 & 0,20 & 0,00 & 0,20 \\
\hline Diplopoda & 0,20 & 0,00 & 0,00 & 0,00 & 0,20 \\
\hline Pauropoda & 0,00 & 0,00 & 0,00 & 14,73 & 14,73 \\
\hline Symphyla & 0,00 & 0,20 & 0,00 & 0,00 & 0,20 \\
\hline Pseudoscorpiones & 0,00 & 0,00 & 0,00 & 0,00 & 0,00 \\
\hline Arachnida & 0,00 & 0,00 & 0,00 & 0,20 & 0,20 \\
\hline Acari & 8,76 & 17,12 & 23,29 & 74,84 & 124,01 \\
\hline Protura & 0,00 & 0,00 & 0,00 & 0,00 & 0,00 \\
\hline Diplura & 0,60 & 0,20 & 1,39 & 1,59 & 3,78 \\
\hline Thysanura & 0,00 & 0,00 & 0,00 & 0,00 & 0,00 \\
\hline Collemb. Arthropleona & 0,20 & 0,00 & 1,00 & 1,99 & 3,19 \\
\hline Collemb. Symphypleona & 0,00 & 1,39 & 0,00 & 0,60 & 1,99 \\
\hline Coleoptera & 0,00 & 0,60 & 0,40 & 0,60 & 1,60 \\
\hline Larvas de Coleoptera & 0,00 & 0,20 & 0,00 & 0,00 & 0,20 \\
\hline Larvas de Diptera & 0,00 & 0,00 & 0,00 & 0,00 & 0,00 \\
\hline Formicidae & 1,99 & 0,00 & 0,40 & 0,00 & 2,39 \\
\hline Homoptera & 0,00 & 0,20 & 0,00 & 0,00 & 0,20 \\
\hline Psocoptera & 0,20 & 0,20 & 0,60 & 0,00 & 1,00 \\
\hline Outros & 0,00 & 0,40 & 0,20 & 0,00 & 0,60 \\
\hline \multirow[t]{2}{*}{ Total } & 11,94 & 20,50 & 27,47 & 94,55 & 154,46 \\
\hline & \multicolumn{5}{|c|}{ Solo 6} \\
\hline Mollusca & 0,00 & 0,00 & 0,00 & 0,00 & 0,00 \\
\hline Isopoda & 0,00 & 0,60 & 0,00 & 0,00 & 0,60 \\
\hline Chilopoda & 0,60 & 0,00 & 0,00 & 0,80 & 1,40 \\
\hline Diplopoda & 0,00 & 0,00 & 0,00 & 0,00 & 0,00 \\
\hline Pauropoda & 0,20 & 0,00 & 0,00 & 1,00 & 1,20 \\
\hline Symphyla & 0,20 & 0,40 & 1,00 & 1,19 & 2,79 \\
\hline Pseudoscorpiones & 0,00 & 0,00 & 0,00 & 0,00 & 0,00 \\
\hline Arachnida & 0,60 & 0,60 & 0,40 & 0,20 & 1,80 \\
\hline Acari & 32,25 & 149,48 & 150,28 & 10,15 & 342,16 \\
\hline Protura & 0,00 & 2,19 & 0,20 & 6,17 & 8,56 \\
\hline Diplura & 0,00 & 6,17 & 0,20 & 0,20 & 6,57 \\
\hline Thysanura & 0,00 & 0,00 & 0,00 & 0,00 & 0,00 \\
\hline Collemb. Arthropleona & 3,58 & 17,71 & 24,48 & 9,36 & 55,13 \\
\hline Collemb. Symphypleona & 0,20 & 0,20 & 0,00 & 0,00 & 0,40 \\
\hline Coleoptera & 0,20 & 2,59 & 1,59 & 3,78 & 8,16 \\
\hline Larvas de Coleoptera & 0,20 & 0,20 & 0,00 & 0,40 & 0,80 \\
\hline Larvas de Diptera & 0,00 & 0,00 & 0,20 & 0,00 & 0,20 \\
\hline Formicidae & 7,36 & 18,71 & 21,70 & 10,75 & 58,52 \\
\hline Homoptera & 0,40 & 5,77 & 0,40 & 0,00 & 6,57 \\
\hline Psocoptera & 0,20 & 0,20 & 0,80 & 0,60 & 1,80 \\
\hline Outros & 1,00 & 1,00 & 2,39 & 1,79 & 6,18 \\
\hline Total & 46,97 & 205,81 & 204,62 & 46,38 & 503,78 \\
\hline
\end{tabular}

(1) Média de 20 repetições, coletadas na profundidade de 0 a $5 \mathrm{~cm}$. 
A população de Collembola Arthropleona foi altamente correlacionada com as populações de Symphyla $\left(\mathrm{r}=0,91^{* * *}\right)$, Acari $\left(0,82^{* * *}\right)$, Protura $\left(0,83^{* * *}\right)$ e Diplura $\left(0,69^{* *}\right)$. Já a população de Collembola Symphypleona correlacionou-se bem apenas com a população de Psocoptera $\left(0,81^{* * *}\right)$.

Outro grupo identificado foi o Formicidae, o qual apareceu com maior número de indivíduos nos solos 6, 1, 2 e 3 (Quadro 6). As condições físicas desfavoráveis (baixa capacidade de campo e teor de argila - Quadro 2) e a compactação observada em campo não estimularam o desenvolvimento desse grupo no solo 5. Segundo Stary \& Kubiznáková (1987), os organismos do grupo Formicidae são altamente tolerantes a metais pesados.

Foram encontrados ainda os seguintes grupos: Pauropoda, Symphyla, Aracnideos, Protura, Diplura, Homoptera, Coleoptera e Psocoptera. O grupo Pauropoda apareceu em maior densidade populacional e mais regularmente nos solos 1 e 3 . Cabe ressaltar que a grande densidade populacional desse grupo no solo 5 na coleta de janeiro deve-se, provavelmente, à coleta ao acaso de colônias desses animais.

O grupo dos aracnídeos não apareceu no solo 5, e no solo 2 esse grupo apenas foi detectado na coleta de setembro. Nota-se que o grupo manteve-se praticamente constante durante as épocas de amostragem no solo 1 (referência). O solo 3 apresentou maior densidade populacional total de aracnídeos (somatório das quatro coletas) e um intenso pico populacional no mês de setembro. Houve favorecimento deste grupo nos solos com maior teor de $\mathrm{Pb}$ extraído com $\mathrm{HNO}_{3} 0,5 \mathrm{~mol} \mathrm{~L}^{-1}\left(\mathrm{r}=0,76^{* * * *}\right)$, possivelmente devido à redução de organismos competidores (os aracnídeos são predadores).

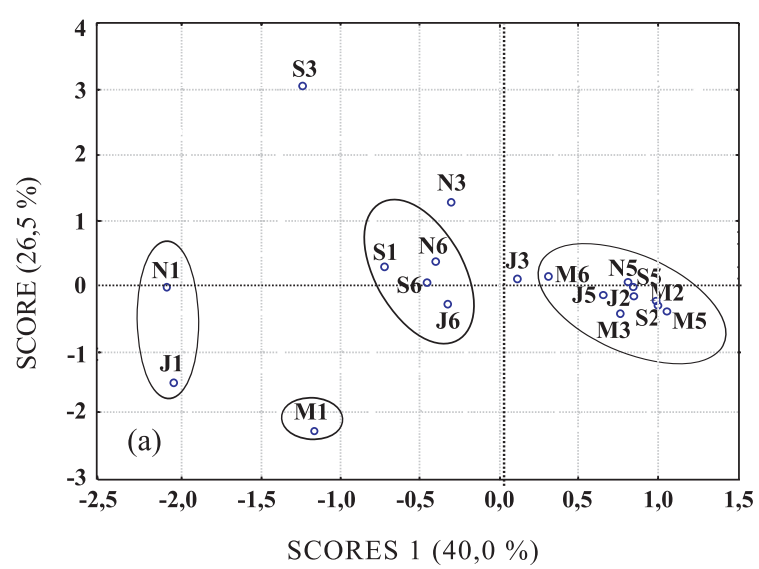

O grupo Symphyla apareceu com maior regularidade nos solos 1 e 6, os quais possuem menores teores de $\mathrm{Pb}$ (Quadro 4). A densidade populacional total dos grupos Coleoptera e Protura também foi superior nesses solos.

As densidades populacionais do grupo Psocoptera foram baixas e semelhantes para todos os solos, com exceção dos maiores valores para o solo 3 . Esse solo apresentou os maiores teores de $\mathrm{Pb} \mathrm{HNO}_{3}$ (Quadro 4). Esse fato pode indicar favorecimento desse grupo no que diz respeito a interferência dos metais pesados menor população de predadores, como observado para os aracnídeos (alta correlação entre esses grupos - $\mathrm{r}=$ $\left.0,97^{* *}\right)$.

Organismos de Mollusca, Isopoda, Pseudoscorpiones e Thysanura foram encontrados apenas no solo 1 (referência). Segundo Yamamoto et al. (1994), os Pseudoscorpiones são bons bioindicadores, já que são sensíveis a ações antrópicas e encontram-se em maiores densidades populacionais em ambientes com maior equilíbrio ecológico.

Observa-se que, ao contrário dos atributos microbiológicos, determinados em amostras coletadas nos mesmos locais do presente estudo (Barros et al., 2010), o agrupamento das amostras na análise por componentes principais (ACP) (Figura 3) foi mais influenciado pela qualidade física e química dos solos (Quadros 2, 3 e 4). Os componentes principais 1 e 2 da ACP explicaram $66,5 \%$ da variabilidade total dos grupos da mesofauna. Houve a formação de três grupos maiores e distintos (quanto maior a proximidade das amostras entre si, maior a homogeneidade do grupo): o primeiro, formado por duas coletas do solo 1 , com certa proximidade da coleta de maio do mesmo solo a esse grupo; o segundo, formado

Figura 3. Análise de Componente Principal dos dados da mesofauna da camada de 0 a 5 cm: diagrama de ordenação das amostras (scores) e formação de grupos de amostras semelhantes (a) e diagrama de ordenamento das variáveis (loadings) (b) levando-se em consideração os componentes principais 1 e 2. NOTA: A letra representa o mês de coleta e o número o solo. M: maio; S: setembro; N: novembro; J: janeiro; a2: Isopoda; a4: Diplopoda; a6: Symphyla; a7: Pseudoscorpiones; a8: Arachnida; a10: Acari; a11: Protura; a14: Collemb. Arthropleona; a15: Collemb. Symphypleona; a17: Coleoptera; a20: Larvas de Diptera; a25: Psocoptera. 
por três coletas do solo 6 e uma do solo 1; e o terceiro, formado por todas as coletas dos solos 2 e 5 e uma coleta dos solos 3 e 6 . Já as amostras do solo 3 , de setembro, novembro e janeiro, ficaram dispersas na parte superior do gráfico de ordenamento das amostras (scores) (Figura 3a).

Posições equivalentes no gráfico de ordenamento das variáveis (loadings) (Figura 3b) em relação ao gráfico de scores indicam as variáveis que tiveram maior peso na separação dos grupos de amostras mais homogêneas. Por exemplo, verifica-se que as amostras do solo 1 coletadas em maio, novembro e janeiro (M1, $\mathrm{N} 1$ e J1), posicionadas mais à direita do gráfico, apresentaram maiores densidades populacionais de Pseudoscorpiones (Quadro 6), sendo a ligeira dispersão da amostra M1 em relação a N1 e J1 ocasionada pelas maiores densidades populacionais de Isopoda em M1 e pelas maiores densidades populacionais de Symphyla em N1 e J1 (Figura 3 e Quadro 6). A aproximação das amostras M1, J1 e N1 também foi influenciada pelas suas maiores quantidades de larvas de Diptera.

A formação do segundo grupo (N6, S6, J6 e S1) foi fortemente influenciada pelas quantidades intermediárias de Coleoptera e Protura (Figura 3b e Quadro 6). A ocorrência desses organismos nos demais solos contaminados com $\mathrm{Pb}$ (2, 3 e 5) foi desprezível. A distinção da maioria das amostras do solo 6 em um grupo homogêneo também está coerente com seus menores teores de $\mathrm{Pb}$ (Quadro 4) em relação aos solos contaminados. Já o terceiro grupo foi definido pelas menores quantidades de todos os organismos (solos 2 e 5) e também pela menor riqueza de grupos de organismos (observar ausência de variáveis da mesofauna no gráfico em posição equivalente Figura 3b).

As justificativas para o isolamento das amostras de setembro, novembro e janeiro do solo 3 são: em setembro, principalmente pela maior densidade populacional de Acari e aracnídeos; em novembro, devido à maior semelhança com as amostras do solo 6 (comparar as coletas do mês de novembro dos referidos solos - Quadro 6); e em janeiro, devido à população de Coleoptera, a qual apareceu apenas nesta coleta.

Em relação aos valores totais médios (considerando as quatro coletas) da densidade populacional dos organismos em relação aos solos, tem-se a seguinte sequência decrescente (número de indivíduos $\mathrm{dm}^{-3} \mathrm{de}$ solo - Quadro 6): solo $3(178,2) \sim$ solo $1(174,9)>$ solo $6(125,9)>$ solo $5(38,2)>$ solo $2(32,1)$. Sequência similar foi verificada para o Índice de Qualidade Ambiental da Mesofauna (IQAMe) médio (Quadro 7): solo $1(16,6)>3(10,5)>6(8,7)>5(2,3) \sim 2(1,9)$.

$\mathrm{O}$ solo 3, com maior teor de $\mathrm{Pb} \mathrm{HNO}_{3}$ (Quadro 4), apresentou densidades populacionais de grupos de organismos similares às do solo 1 (referência), pela melhor qualidade física e química desse sítio (Quadros 2 e 3), conforme demonstrado na ACP realizada por Barros (2008). Destacam-se a alta fertilidade do solo (altos valores para soma de bases,
Quadro 7. Valores de índices de qualidade ambiental da mesofauna (IQAMe) para a camada de 0 a 5 cm dos solos

\begin{tabular}{rrrrrr}
\hline Solo & Maio & Setembro & Novembro & Janeiro & Média \\
\hline 1 & 6,14 & 8,76 & 35,63 & 16,01 & 16,64 \\
2 & 1,51 & 1,80 & 1,27 & 2,90 & 1,87 \\
3 & 1,83 & 24,22 & 12,59 & 3,22 & 10,46 \\
5 & 0,97 & 1,65 & 1,93 & 4,74 & 2,32 \\
6 & 2,88 & 12,58 & 13,40 & 5,97 & 8,71 \\
\hline
\end{tabular}

saturação por bases, CTC total, N total, C orgânico e os maiores teores de $\mathrm{K}^{+}$trocável e $\mathrm{P}$ disponível Quadro 3) e a cobertura arbórea com leguminosas (Leucaena sp.) (Quadro 1). Esses dados reforçam a constatação de que apenas a contagem total de organismos não reflete a qualidade do ambiente em relação ao nível de contaminação por metais pesados. Em condições físicas e químicas de solo adequadas para o crescimento da mesofauna, possivelmente, os organismos foram menos sensíveis ao estresse por metais pesados ou ficaram mais aptos a desenvolverem mecanismos de resistência à toxidez por esses poluentes. De acordo com Rainbow (2002) e Vijveret et al. (2004), as principais adaptações de resistência da mesofauna a metais pesados são: limitar a bioacumulação por excreção ativa e, ou, redução da absorção; e armazenar os elementos sob formas não tóxicas, como grânulos envoltos por proteínas.

Devido à menor qualidade física e química dos demais solos contaminados (2, 5 e 6) (Quadros 2 e 3), a sequência decrescente do número total médio de organismos e do IQAMe $(6>5>2)$ foi em sentido oposto ao aumento nos teores de $\mathrm{Pb} \mathrm{HNO}_{3}$ (Quadro 4).

\section{$\mathrm{Pb}$ e Zn em formigas}

Em razão da pequena massa de formigas obtidas no solo 5 (da ordem de 0,0009 g), não se determinaram os teores de $\mathrm{Pb}$ e Zn nessa amostra. A acumulação de $\mathrm{Pb}$ pelo grupo Formicidae (solo 1 - 11,5 < 6 - 13,4<2 - 70,5<3 - 84,6 $\mathrm{mg} \mathrm{kg}^{-1}$ ) seguiu a mesma sequência em ordem crescente dos teores de $\mathrm{Pb}$ no solo (Quadro 4). Os teores de $\mathrm{Zn}$ nas formigas variaram de 80,8 a $184,6 \mathrm{mg} \mathrm{kg}^{-1}$.

Considerando as formigas do solo 1 (referência), verifica-se que a taxa de acumulação de $\mathrm{Pb}$ nos solos 2 e 3 foi muito superior, com provável prejuízo ao bom funcionamento desses organismos. Migula et al. (1997) observaram efeito extremamente tóxico da acumulação de $\mathrm{Cd}$ e $\mathrm{Hg}$ sobre o funcionamento metabólico em formigas vermelhas, como alterações das funções enzimáticas.

Apesar de ser bom indicador do nível de metais pesados nos solos, na prática é difícil obter massa suficiente de organismos da mesofuna para a digestão das amostras com a coleta por meio de funis de Berlese. 


\section{$\mathrm{Pb}$ e $\mathrm{Zn}$ em plantas}

As Poaceae apresentaram menores teores de $\mathrm{Pb}$ nas raízes e parte aérea no solo 1 (Quadro 8). A absorção e o acúmulo de Zn na parte aérea e raízes foram altamente correlacionados aos teores extraídos com $\mathrm{HNO}_{3}$ nos solos $\left(\mathrm{r}=0,90^{* * * *}\right.$ e $0,70^{* * *}$, respectivamente). Para o $\mathrm{Pb}$, essa relação direta foi observada apenas nas raízes $\left(\mathrm{r}=0,82^{* * * *}\right)$. A absorção de $\mathrm{Pb}$ e $\mathrm{Zn}$ foi dificultada nos solos mais argilosos ( $\mathrm{r}$ com o teor de argila $=-0,66^{* *}$ e $-0,65^{* *}$, respectivamente).

As plantas que cresceram no solo 3 (coletas de setembro e novembro), com maiores teores de $\mathrm{Pb}$ $\mathrm{HNO}_{3}$, também apresentaram as maiores concentrações desse metal nas raízes. Como possível mecanismo de tolerância aos elevados teores de $\mathrm{Pb}$ no solo 3, a translocação do metal das raízes para a parte aérea foi menos intensa (Quadro 8).

A grama-batatais (Paspalum notatum), cobertura vegetal dos solos 2 e 5 , apresentou as maiores concentrações de $\mathrm{Pb}$ na parte aérea. O capim-colonião (Panicum maximum), presente no solo mais

\section{Quadro 8. Teores de $\mathrm{Pb}$ e $\mathrm{Zn}$ na parte área e raiz das} Poaceae $^{(1)}$

\begin{tabular}{|c|c|c|c|c|}
\hline Coleta & Solo & Tipo & $\mathbf{P b}$ & $\mathrm{Zn}$ \\
\hline & & & $-\mathrm{m}$ & $\mathrm{kg}^{-1}$ \\
\hline & & Parte aérea & & \\
\hline \multirow[t]{5}{*}{ Setembro } & 1 & Capim -Colonião & 16,89 & 157,70 \\
\hline & 2 & Grama-Batatais & 182,04 & 241,11 \\
\hline & 3 & Capim -Colonião & 171,39 & 218,20 \\
\hline & 5 & Grama-Batatais & 575,53 & 1355,73 \\
\hline & 6 & Capim-Elefante & 47,15 & 134,08 \\
\hline \multirow[t]{5}{*}{ Novembro } & 1 & Capim - Colonião & 19,86 & 191,72 \\
\hline & 2 & Grama-Batatais & 90,02 & 142,77 \\
\hline & 3 & Capim - Colonião & 126,05 & 238,66 \\
\hline & 5 & Grama-Batatais & 512,16 & 1109,83 \\
\hline & 6 & Capim-Elefante & 102,55 & 113,54 \\
\hline \multirow[t]{6}{*}{ Janeiro } & 1 & Capim -Colonião & nd & nd \\
\hline & 2 & Grama-Batatais & 3,06 & nd \\
\hline & 3 & Capim -Colonião & 13,28 & 225,42 \\
\hline & 5 & Grama-Batatais & 211,35 & 637,29 \\
\hline & 6 & Capim - Elefante & nd & nd \\
\hline & & Raiz & & \\
\hline \multirow[t]{5}{*}{ Setembro } & 1 & Capim -Colonião & 22,65 & 59,94 \\
\hline & 2 & Grama-Batatais & 99,80 & 531,76 \\
\hline & 3 & Capim -Colonião & 939,96 & 184,81 \\
\hline & 5 & Grama-Batatais & 376,07 & 1317,38 \\
\hline & 6 & Capim-Elefante & 164,90 & 245,67 \\
\hline \multirow[t]{5}{*}{ Novembro } & 1 & Capim -Colonião & 12,67 & 89,44 \\
\hline & 2 & Grama-Batatais & 122,90 & 738,12 \\
\hline & 3 & Capim -Colonião & 733,68 & 1127,63 \\
\hline & 5 & Grama-Batatais & 420,88 & 1851,72 \\
\hline & 6 & Capim-Elefante & 129,96 & 455,33 \\
\hline \multirow[t]{5}{*}{ Janeiro } & 1 & Capim -Colonião & 24,14 & 428,92 \\
\hline & 2 & Grama-Batatais & 74,04 & 532,72 \\
\hline & 3 & Capim -Colonião & 414,72 & 481,18 \\
\hline & 5 & Grama-Batatais & 436,45 & 730,52 \\
\hline & 6 & Capim-Elefante & 168,17 & 647,85 \\
\hline
\end{tabular}

(1) nd: teor abaixo do nível de detecção por ICP-AES. contaminado (solo 3) e no solo de referência (solo 1), foi sensível ao teor de metais pesados na área. Apesar dos baixos níveis de $\mathrm{Pb}$ na parte aérea do capimelefante (Pennisetum purpureum) (solo 6), a elevada produção de biomassa aumentou o potencial dessa espécie em trabalhos de fitorremediação da área.

Comparando os teores de metais pesados na parte aérea (Quadro 8) com os teores de toxidez apresentados por Kabata-Pendias \& Pendias (2001) para Pb (30$300 \mathrm{mg} \mathrm{kg}^{-1}$ ) e Zn (100-400 mg kg-1), observa-se que, com exceção do solo 1, todas as plantas estão sob efeito fitotóxico. Com base nesses resultados, sugere-se deixar a área sob pousio, não permitindo o pastoreio por animais.

\section{CONCLUSÕES}

1. O número total de organismos dos 21 grupos identificados e o Índice de Qualidade Ambiental da Mesofauna não foram bons indicadores dos níveis de contaminação dos solos por metais pesados.

2. A ocorrência e distribuição de grupos isolados mostraram-se mais eficientes nesse propósito. A melhor qualidade ambiental do solo de referência (menores teores de $\mathrm{Pb}$ e $\mathrm{Zn}$ ) foi atestada pela maior riqueza de grupos de organismos e ocorrência de representantes dos grupos Pseudoscorpiones, Mollusca e Isopoda apenas nesse solo.

3. Os grupos Arachnida e Psocoptera também foram considerados bons indicadores ambientais, com incremento de suas populações nos solos com maiores teores de $\mathrm{Pb}$ e Zn, possivelmente pela menor ocorrência de organismos competidores/predadores desses grupos.

4. A Análise por Componentes Principais para a mesofauna refletiu os teores de $\mathrm{Pb}$ e $\mathrm{Zn}$ e a qualidade física e química dos solos - condição desejável nos estudos de bioindicadores.

5. Os teores de $\mathrm{Pb}$ nos indivíduos do grupo Formicidae tiveram relação direta com os teores do elemento no solo. Os maiores teores de $\mathrm{Pb}$ e $\mathrm{Zn}$ foram encontrados nas raízes das plantas, sobretudo nos solos mais contaminados.

\section{LITERATURA CITADA}

ANDRADE, M.G.; MELO, V.F.; GABARDO, J.; SOUZA, L.C.P. \& REISSMANN, C.B. Metais pesados em solos de área de mineração e metalurgia de chumbo: I - fitoextração. R. Bras. Ci. Solo, 33:1879-1888, 2009a.

ANDRADE, M.G.; MELO, V.F.; SOUZA, L.C.P.; GABARDO, J. \& REISSMANN, C.B. Metais pesados em solos de área de mineração e metalurgia de chumbo: I - formas e disponibilidade. R. Bras. Ci. Solo, 33:1889-1897, 2009 b. 
BAKER A.J.M. Accumulators and excluders - strategies in the response of plants to heavy metals. J. Plant Nutr., 3:643-654, 1981.

BARROS, Y.B. Indicadores biológicos de qualidade de solos de área de mineração e processamento de chumbo, no município de Adrianópolis (PR). Curitiba, Universidade Federal do Paraná, 2008. 109p. (Tese de Mestrado)

BARROS, Y.J.; MELO, V.F.; DIONÍSIO, J.A.; CARON, L.; OLIVEIRA, E.B.; AZEVEDO, J.C.R.; SOUZA, L.C.P. \& KUMMER, L. Indicadores de qualidade de solos de área de mineração e metalurgia de chumbo. II - Avaliações na mesofauna e em plantas. R. Bras. Ci. Solo, 34:1413-1426, 2009 .

BEHAN, V. A.; STUART, B. B. \& MCKEVAN, D. K. Effects of Nitrogen fertilizers, as urea, on Acarina and other arthropods in Quebec black spruce humus. Pedobiologia, 18:249-263, 1978.

BENGTSSON, G. \& RUNDGREN, S. The Gusum case: A brass mill and the distribution of soil Collembola. Can. J. Zool., 66:518-526, 1988

CHRISTIANSEN, K. Bionomics of Collembola. Ann. Rev. Entomol., 9:147-178, 1964.

CURRY, J.P. \& GOOD, J.A. Soil fauna degradation and restoration. Adv. Soil Sci., 17:171-215, 1992.

EEVA, T.; RYO, M. \& RIIHIMA, J. Pollution-related changes in diets of two insectivorous passerines. Oecologia, 145:629-639, 2005

EMPRESA BRASILEIRA DE PESQUISA AGROPECUÁRIA EMBRAPA. Manual de análises químicas de solos, plantas e fertilizantes. Brasília, Embrapa Comunicação para Transferência de Tecnologia, 1999. 370p.

EYSINK, G.G.J. Metais pesados no Vale do Ribeira e em Igunde-Cananéia. R. CETESB Tecnol., 2:6-13, 1988.

FILSER, J.; FROMM, H.; NAGEL, R. \& WINTER, K. Effects of previous intensive agricultural management on microorganisms and the biodiversity of the soil fauna. Plant Soil, 170:123-129, 1995.

FISHER, R.F. \& BINKLEY, D. Ecology and management of forest soils. 3.ed. London, John Wiley, 2000. 489p.

FRANKLIN, E.; MAGNUSSON, W.E. \& LUIZÃO, F.J. Relative effects of biotic and abiotic factors on the composition of soil invertebrate communities in an Amazonian savanna. Applied Soil Ecol., 25:231-239, 2005.

HAAN, S. Results of municipal waste compost research over more than fifty years at the Institute for soil fertility at Hare/Groningen, the Nertherlands, Neth. J. Agric. Sci., 29:49-61, 1981.

JACKSON, M.L. Soil chemical analysis - advanced course. Madison, Prentice-Hall, 1970. 895p.

JONES JR, J.B.; ECK, H.V. \& VOSS, R. Plant analysis as an aid in fertizing corn and grain sorghum. In: WESTERMAN, R.L.; BAIRD, J.V.; CHRISTENSEN, N.W.; FIXEN, P.E. \& WHITNEY, D.A., eds. Soil testing and plant analysis. 3.ed. Madison, Soil Science Society of America, 1990. p.521-547.
KABATA-PENDIAS, A. \& PENDIAS, H. Trace elements in soils and plants. 3.ed. Boca Raton, CRC Press, 2001. 413p.

KAISER, E.A.; HEISLER, C.; WALENZIK, G. \& HEINEMEYER, O. The effect of mechanical soil compaction on microbial biomass development, Collembolan fauna, denitrification and mineralization in an agricultural location. Mitteilungen Deutschen Bodenkund. Gesellschaft, 66:531-534, 1991.

KNUDSEN, D.; PETERSON, G.A. \& PRATT, P.F. Lithium, sodium and potassium. In: PAGE, A. L., ed. Methods of soil analysis. Part 2. Chemical and microbiological properties, American Society of Agronomy. Madison, 1986. p.225-246.

LANNO, R.; WELLS, J.; CONDER, J.; BRADHAM, K. \& BASTA, N. The bioavailability of chemicals in soil for earthworms. Ecotoxicol. Environ. Safety, 57:39-47, 2004.

LIM, C.H. \& JACKSON, M.L. Dissolution for total elemental analysis. In: PAGE, A.L., ed. Methods of soil analysis. Parte 2: Chemical and microbiological poperties. Madison, American Society of Agronomy, 1986. p.1-12.

MARTINS, R.; MELO, V.F. \& MONTE SERRAT, B. Métodos de determinação da disponibilidade de potássio para a cultura do trigo em solos dos Campos Gerais, Estado do Paraná. R. Ceres, 51:787-801, 2004.

MELO, V.F.; SCHAEFER, C.E.G.R.; NOVAIS, R.F.; SINGH, B. \& FONTES, M.P.F. Potassium and magnesium in clay minerals of some Brazilian soil as indicated by a sequential extraction procedure. Comm. Soil Sci. Plant Anal., 33:22032225,2002 .

MIGULA, P.; GÈOWACKA NUORTEVA, S.L.; NUORTEVA, P. \& TULISALO, E. Time-related effects of intoxication with cadmium and mercury in the red wood ant. Ecotoxicology, 6:307-320, 1997.

MUSSURY, R.M.; SCALON, S.P.Q.; SILVA, S.V. \& SOLIGO, V.R. Study of acari and collembola populations in four cultivation systems in Dourados - MS. Braz. Arch. Biol. Technol., 45:257-264, 2002.

OLSEN, S.R. \& SOMMERS, L.E. Phosphorus. In: PAGE, A.L., ed. Methods of soil analysis. Part 2. Chemical and microbiological properties. Madson, American Society of Agronomy, 1982. p.421-422.

PAOLETTI, M.G. \& BRESSAN, M. Soil invertebrates as bioindicators of human disturbance. Critical Rev. Plant Sci., 15:21-62, 1996.

RAINBOW, P.S. Trace metal concentrations in aquatic invertebrates: Why and so what? Environ. Pollution, 120:497-507, 2002.

SANGINGA, N.; MULONGOY, K. \& SWIFT, M.J. Contribution of soil organisms to the sustainability and productivity cropping systems in the tropics. Agric. Ecosyst. Environ., 41:135-152, 1992.

SAUTTER, K.D. Efeito da compactação de um Latossolo Vermelho-Escuro, causada pela colheita de Eucalyptus grandis, sobre alguns organismos do solo. Curitiba, Universidade Federal do Paraná, 2001. 105p. (Tese de Doutorado) 
SAUTTER, K.D. \& SANTOS, H.R. Avaliação da estrutura da população da mesofauna edáfica, em diferentes regimes de reabilitação de um solo degradado pela mineração do xisto. R. Ci. Agr., 13:31-34, 1994.

SAUTTER, K.D.; SANTOS, H.R. \& RIBEIRO JUNIOR, P.J. Comparação das comunidades de Entomobryidae e Isotomidae (Collembola) entre plantio direto em três níveis de fertilidade, plantio convencional e um ecossistema natural (campo) em Ponta Grossa, Paraná, Brasil. R. Bras. Zool., 16:117-124, 1999

SEASTED, T.R. The role of microarthropods in decomposition and mineralization processes. Ann. Rev. Entomol., 29:2546, 1984.
SINGH, J. \& PILLAI, K.S. A study of soil microarthropod communities in same fields. Rev. Ecol. Sol, 12:579-590, 1975 .

STARY, P. \& KUBIZNÁKOVÁ, J. Content and transfer of heavy metal air pollutants in populations of Formica spp. wood ants (Hym, Formicidae). J. Appl. Entomol., 104:110, 1987.

STORK, N.E. \& EGGLETON, P. Invertebrates as determinants and indicators of soil quality. Am. J. Alter. Agric., 7:38-47, 1992.

TEIXEIRA, L.B. \& SCHUBART, H.O.R. Mesofauna do solo em áreas de floresta e pastagem na Amazônia Central. Belém, Embrapa/CPATU, 1988. 16p. (Boletim de Pesquisa, 95) 